том, что в дошкольных учебных учреждениях отсутствует специальная речевая работа по формированию у детей старшего дошкольного возраста умений и навыков аудирования.

Ключевые слова: аудирование, умения и навыки аудирования, восприятие речи, понимание речи, речевая деятельность.

Olesia Shafran (Korop), post-graduate student, Department of Psychology and Pedagogy of Preschool Education, Pereyaslav-Khmelnytskyi State Pedagogical University named after Hryhoriy Skovoroda, 30, Sukhomlynskyi Str., Pereyaslav-Khmelnytskyi, Ukraine

\title{
ACTIVITY PROGRESS OF PRESCHOOL EDUCATIONAL INSTITUTIONS ON THE FORMATION OF THE LISTENING COMPREHENSION SKILLS IN SENIOR PRESCHOOLERS
}

The article is aimed at revealing the real activity progress of preschool educational institutions on the formation of listening comprehension skills in senior preschoolers. The following methods were used: survey of pedagogues; monitoring of the educational process in kindergartens; study and review of the curricula; review of the content of child readers in kindergartens. Questioning of pedagogues has shown that most of them realize the importance of the researched issue for the development of preschool children's speech. However, they have not enough knowledge about the phenomenon of "listening comprehension", peculiarities of the formation of listening comprehension skills in preschoolers (pedagogical conditions, methods and techniques, forms and means of speech and developing work with children), criteria and indicators of the levels of the development of these skills. They do not have enough knowledge about what kind of listening skills and abilities should be formed in preschoolers. Therefore, we believe that teaching staff need theoretical and practical knowledge on the formation of listening comprehension skills in preschoolers during the educational process. The monitoring of the educational process has shown that during language development lessons of senior preschoolers the teachers focus their attention primarily on the development of their speaking skills (different kinds and types of stories, retelling, inventing stories, etc.). The review of the content of child readers has shown that they have no specific tasks (comments, questions) aimed at the development of listening comprehension skills in preschoolers. The carried out research has shown that that preschool educational institutions do not provide purposeful educational work focused on the development of listening comprehension skills in senior preschoolers.

Keywords: listening, listening skills and abilities, speech perception, understanding of speech, speech activity.

Подано до редакиіï 14.04.2016

Рецензент: д. пед. н., проф. І. І. Доброскок

Софія Дмитрівна Рой, аспірант кафедри педагогіки, Південноукраӥнський національний педагогічний університет імені К. Д. Ушинського, вул. Старопортофранківська, 26, м. Одеса, Украӥна

\section{ІНДИВІДУАЛЬНІ ОСВІТНІ ТРАЕКТОРІЇ ЯК ЗАСІБ ПІДВИЩЕННЯ ІНФОРМАЦИЙНОЇ КУЛЬТУРИ МАЙБУТНІХ УЧИТЕЛІВ}

У статті розглянуто сутність понять «інформаційна культура особистості» та «індивідуальна освітня траєкторія». Під інформаціийнюю культурою фахівия розуміємо інтегральне особистісне утворення, щзо містить знання, вміння та навички щуодо володіння сучасними інформаційними технологіями. Індивідуальну освітню траєкторію трактуємо як вид індивідуалізаџії та диференціачії навчання, щзо проявляється у виборі студентом змісту, иілей, методів і засобів навчання відповідно до його інтересів, здібностей та мотивацій, яка реалізується у співробітництві з викладачем. Окреслено шляхи підвищення інформаційної культури майбутніх учителів за допомогою індивідуальних освітніх траєкторій у прочесі вивчення іноземної мови.

Ключові слова: інформачійна культура, індивідуальна освітня траєкторія, індивідуальний освітній маршрут, індивідуальна освітня програма, майбутні вчителі.

Актуальність дослідження зумовлена стрімким розвитком інформаційних технологій та необхідністю підготовки майбутніх спеціалістів до їх використання. Завданням сучасної освіти є забезпечення майбутнього спеціаліста необхідними навичками та вміннями для ефективної праці в інформаційному суспільстві. У зв'язку з цим великого значення набуває дослідження інформаційної культури особистості.
Високий рівень означеної культури забезпечує здатність фахівця знаходити та обробляти необхідну інформацію, опановувати нові інформаційні технології та вдосконалювати професійні вміння. Отже, формування інформаційної культури майбутніх фахівців у процесі професійної підготовки є найважливішим завданням освіти сьогодення. 
Аналіз літератури. Проблему формування інформаційної культури фахівців досліджували В. П. Беспалько, В. В. Васильєв, Г. Г. Воробйов, Б. С. Гершунський, Е. В. Данильчук, В. Г. Кінельов, С. І. Машбіц, В. Л. Матросова, І. Ф. Харламов та ін.

Уперше термін «інформаційна культура» в науковій літературі з'явився в 1971 в працях Г. Г. Воробйова. Сучасні дослідники по-різному трактують поняття «інформаційна культура». Так, Є. П. Семенюк під інформаційною культурою розуміє «інформаційну компоненту людської культури в цілому, що об'єктивно характеризує рівень всіх здійснюваних у суспільстві інформаційних процесів та існуючих інформаційних відносин» [7]. В. А. Кравець і В. Н. Кухаренко розглядають інформаційну культуру як сукупність принципів і механізмів, що забезпечують взаємодію етнічних і національних культур, їх з'єднання в загальний досвід людства. М. О. Антонченко трактує інформаційну культуру людини як системне утворення особистості, яке інтегрує знання про специфіку застосування інформаційних технологій, уміння використовувати наявну інформацію для вирішення прикладних завдань, навички використання персонального комп'ютера і технологій зв'язку; орієнтує на розширення та оновлення знань [1].

Також існує кілька підходів до формування інформаційної культури майбутніх фахівців, серед яких виокремлюємо компетентнісний, культурологічний, системний, діяльнісний та ін. Свої дослідження проблемі інформаційної культури також присвятили М. М. Левшин, С. М. Оленєв, С. П. Семенюк, Н. Б. Зінов'єва, С. Г. Антонова, М. Н. Назаренко, Р. С. Гуревич, Н. І. Гендіна та ін.

Так, М. М. Левшин зазначає, що формування інформаційної культури доцільно проводити через вивчення різноманітних джерел інформації; опанування способів аналітико-синтетичної переробки навчальної інформації, прийомів і засобів самостійного ведення пошуку інформації відповідно до завдань, які виникають під час навчання; вивчення та застосування можливостей новітніх інформаційних технологій тощо [5].

С. Г. Антонова вважає інформаційну культуру важливою складовою духовної культури і розглядає іiі як якісну характеристику особистості. Автор підкреслює, що гуманітарний аспект інформаційної культури спрямований на виховання духовності, натхненності особистості, етичного та естетичного ставлення до навколишнього середовища.

Проблема застосування індивідуальних освітніх траєкторій у навчальному процесі ВНЗ була віддзеркалена у працях науковців С. О. Александрової, І. С. Якиманської, П. В. Сисоєва, С. А. Вдовіної, Є. Г. Срикової, М. Н. Костикової, Н. Г. Звєрєвої, В. В. Лоренц та ін.

Сутність феномену «індивідуальна траєкторія розвитку» теоретично обгрунтовано I. С. Якиманською у 1994 р. Авторка під індивідуальною освітньою траєк- торією розуміє персональний шлях реалізації особистісного потенціалу кожного учня.

Аналіз психолого-педагогічної літератури показує, що наразі існує чимала кількість підходів до визначення індивідуальних освітніх траєкторій. Так, представники особистісно-процесуального підходу (Л. В. Глазкіна, С. В. Воробйова, Н. В. Землянська, П. В. Сисоєв та ін.) розглядають індивідуальну освітню траєкторію як персональний шлях досягнення поставленої освітньої мети (або навчальної задачі) конкретним учнем, відповідний до його здібностей, мотивів, інтересів і потреб.

3 точки зору представників особистісного підходу (Ю. Г. Юдіна, Є. П. Черняєва, Т. В. Машкова, С. А. Вдовіна, Є. Г. Срикова та ін.), важливим є активна участь, того хто навчається, у виборі змісту, форм, методів навчання. Індивідуальна освітня траєкторія студента визначається ними як форма індивідуалізації та диференціації професійної освіти, що базується на свободі вибору студентом цілей, змісту, форм, методів, засобів, способів рефлексії та темпу навчання у спільній діяльності з викладачем.

Представники третього підходу визначають індивідуальну освітню траєкторію через поняття освітньої програми навчальної дисципліни чи комплексу дисциплін. Так, Н. В. Боброва зазначає, що індивідуальна освітня траєкторія - це програма опанування тим, хто навчається, дисципліною (фрагментом дисципліни) на основі врахування його особистісного потенціалу та формування властивостей, що складають цей потенціал [2]. Схожої думки дотримуються також Є. О. Александрова, О. В. Шеромова, М. Н. Костикова та ін.

У рамках визначених підходів ученими було визначено співвідношення між феноменами «індивідуальні освітні траєкторії», «індивідуальний освітній маршрут» та «індивідуальна освітня програма». Дослідники (Г. І. Ковальова, I. Є. Каньковський, Н. Г. Звєрєва та ін.) вважають за необхідне диференціювати ці поняття. Так, Н. Г. Звєрєва зазначає, що індивідуальний освітній маршрут та індивідуальна траєкторія відображають урахування індивідуальних особливостей учнів, при цьому індивідуальна освітня траєкторія є реалізованим індивідуальним освітнім маршрутом [4]. Учені (С. А. Александрова, Н. В. Рибалкіна, А. А. Кирсанов та ін.) ототожнюють поняття «індивідуальні освітні траєкторії/маршрути». В. Г. Срикова зазначає, що ці поняття є синонімічними та визначає індивідуальну освітню програму як особистісно зорієнтовану організацію студента на основі нормативних вимог і навчального плану, що забезпечує формування у нього індивідуального стилю самоосвітньої діяльності та поетапне освоєння основних компетенцій у процесі професійної підготовки [3].

Наявність різноманітних підходів до визначення сутності означеного феномену сприяло виникненню різноманітних класифікацій індивідуальних освітніх траєкторій. Так, Є. О. Александрова класифікує ці траєкторії в залежності від напряму освітніх інтересів. Вона 
поділяє траєкторії на навчальні (знаннєво зорієнтовані, творчо зорієнтовані, практико зорієнтовані) та виховні (особистісно зорієнтовані, соціально зорієнтовані).

А. С. Гаязов ступенем самостійності мислення виділяє такі індивідуальні освітні траєкторії: маршрут адаптивного типу (вимагає використання освіти для підготовки себе до сучасної соціоекономічної та культурної ситуації); маршрут розвиваючої спрямованості (характеризується широким розвитком можливостей, здібностей і всього творчого потенціалу людини); маршрут творчої спрямованості (включає в себе не тільки розвиток особливостей і можливостей, але i цілеспрямоване їх використання для перетворення, побудови себе, власної освіти, кар'єри, життя).

Інші дослідники класифікують індивідуальні освітні маршрути на основі врахування вікових особливостей людини, інтелектуальної спрямованості діяльності, фактору досвіду та ін.

Незважаючи на велику кількість праць, присвячених дослідженню означених феноменів, проблема використання індивідуальних освітніх траєкторій як засобу підвищення інформаційної культури майбутніх учителів в психолого-педагогічній літературі достатньо відображена не була і потребує більш детального дослідження.

Мета дослідження - теоретичне обгрунтування методики застосування індивідуальних освітніх траєкторій як засобу підвищення інформаційної культури майбутніх учителів.

У межах запропонованого дослідження вважаємо поняття «індивідуальна освітня траєкторія» та «індивідуальний освітній маршрут» тотожними, виокрем- люючи при цьому поняття «індивідуальна освітня програма».

Індивідуальну освітню траєкторію (маршрут) трактуємо як вид індивідуалізації та диференціації навчання, що проявляється у виборі студентом змісту, цілей, методів та засобів навчання відповідно до його інтересів, здібностей та мотивацій, яка реалізується у співробітництві з викладачем.

Індивідуальну освітню програму трактуємо як навчальний план, розроблений 3 урахуванням індивідуальних особливостей учня, що становить основу індивідуального освітнього маршруту.

Під інформаційною культурою фахівця розуміємо інтегроване особистісне утворення що містить знання, вміння та навички щодо володіння сучасними інформаційними технологіями.

На констатувальному етапі експерименту 3 метою виявлення рівня сформованості інформаційної культури (IК) було виокремлено групу респондентів серед студентів Південноукраїнського національного педагогічного університету імені К. Д. Ушинського. Діагностування означеного виду культури було проведено за методикою Є. I Рогова [6]. Надалі по кожному студенту і загалом по кожній групі було підраховано бал, що характеризує рівень сформованості інформаційної культури. На підставі цього, в кожній групі було виокремлено студентів із високим (19-23 балів), достатнім (14-18 балів), середнім (9-13 балів) та низьким (0-9 балів) рівнями сформованості інформаційної культури.

Результати дослідження представлено нижче.

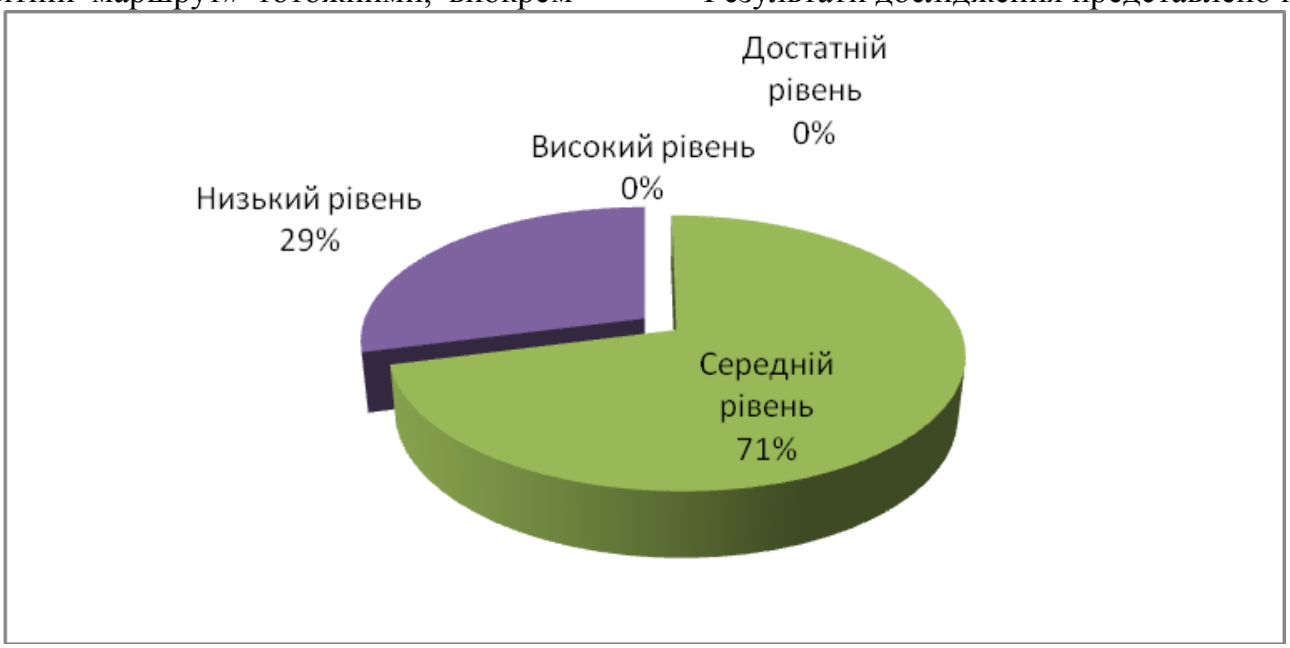

Рис. 1. Результати діагностування рівнів інформаційної культури.

Отримані кількісні дані дають змогу зробити висновок, що рівень інформаційної культури в обраній групі є недостатньо високим, оскільки в жодного в учнів не виявлено високого чи достатнього рівня сформованості інформаційної культури. 3 опитаних респондентів 71\% мають середній рівень, 29\% - низький рівень сформованості інформаційної культури. У зв'язку з цим постає необхідність підвищення рівня інформаційної культури. Одним із таких засобів виступають індивідуальні освітні траєкторії.

Застосування індивідуальних освітніх траєкторій на уроках іноземної мови дає змогу досягти поставленої мети. Цілеспрямовану роботу з формування інформаційної культури майбутніх учителів пропонуємо здійснювати в 3 етапи.

Перший етап спрямований на формування вмінь щодо пошуку, обробки та передавання інформації за 
допомогою мультимедійних редакторів у межах застосування індивідуальних траєкторій адаптивного типу. Використання цих траєкторій вимагає від студента цілеспрямовано організованої освітньої та самоосвітньої діяльності репродуктивного типу. Результатом цього етапу вважаємо здатність студента до пошуку інформації за запитом та оформлення результатів у вигляді електронного документу за зразком.

Так, у процесі вивчення теми «Environmental problems» студентам пропонуємо виконати завдання 3 пошуку та систематизації інформації з теми «Modern environmental problems» за допомогою ресурсів електронних бібліотек та мережі Інтернет. Зміст завдання варіюється в залежності від рівня успішності студента. Студентам із високим рівнем успішності необхідно представити розгорнуту доповідь, яка включає надання визначень основних понять, називає видатних вчених та їх дослідження, що стосуються проблем навколишнього середовища та описує основні екологічні проблеми сучасності. Студенти середнього рівня успішності повинні зосередити свою увагу на описі сучасних проблем навколишнього середовища та їх можливих наслідках. Студенти низького рівня успішності описують екологічні проблеми сьогодення. Результати повинні бути представлені у вигляді доповіді, оформленої за прикладом викладача.

Метою другого етапу є відпрацювання вмінь щодо пошуку, систематизації та передавання інформації за допомогою інформаційно-комунікативних технологій, застосовуючи набуті на першому етапі вміння у нових умовах. Даний етап роботи передбачає використання індивідуальних траєкторій розвивального характеру. Наприкінці другого етапу студенти опановують вміння щодо пошуку інформацію за запитом та представлення результати у вигляді мультимедійної презентації.

На цьому етапі викладач залучає студентів до обговорення теми «Possible solutions of the chosen environmental problems». Наприкінці обговорення студенти обирають найважливішу 3 їх точки зору проблему навколишнього середовища та аргументують можливі іiі рішення, посилаючись на існуючі дослідження 3 цього питання. Результати дослідження студенти представляють у вигляді мультимедійної

\section{ЛІТЕРАТУРА}

1. Антонченко М. О. Інформаційна культура як складова загальнолюдської культури / М. О. Антонченко // Комп’ютерні технології навчання. - 2004. Вип. 9. - С 234-241.

2. Боброва Н. В. Проектирование индивидуальных образовательных траекторий студентов учреждений среднего профессионального образования на основе электронного учебника : автореф. дис. на соискание уч. степени кан. пед. наук : спец. 13.00 .08 «Теория и методика профессионального образования» / Н. В. Боброва. - Калуга, 2011. - 24 с.

3. Ерыкова В. Г. Формирование индивидуальной образовательной траектории подготовки бакалав- презентації. Вимоги до презентації висуваємо різні. Так, студенти високого рівня представляють не менш ніж 20 слайдів, оформлених із використанням відеота аудіосупроводу, анімаційних елементів, гіперпосилань на он-лайн джерела тощо. Студенти середнього рівня успішності створюють презентацію на 18-20 слайдів, обов'язково застосовуючи елементи анімації, аудіо або відео в тілі презентації. Для студентів низького рівня задовільним результатом вважаємо презентацію на 15 слайдів із використанням анімаційних елементів у кожному.

Третій етап формування інформаційної культури майбутніх учителів передбачає творче використання отриманих знань, умінь та навичок щодо роботи 3 інформаційними технологіями. Відповідно доцільним $€$ використання маршрутів творчої спрямованості. Результатом третього етапу вважаємо здатність студентів використати набуті знання, уміння та навички для виконання самостійного творчого завдання.

Так, на завершальному етапі вивчення теми «Environmental problems» пропонуємо кожному студенту розробити план-конспект заняття із зазначеної теми, що містить низку контрольних завдань для перевірки засвоєння навчального матеріалу 3 обов'язковим використанням інформаційних технологій. Надалі кожний студент проводить фрагмент заняття за розробленим конспектом. Зміст завдань залежить від рівня успішності студента. Так, завдання студентів із високим рівнем успішності передбачають виконання навчальних дій щонайменше трьох видів. Студенти середнього рівня складають два завдання (репродуктивне та творче), спираючись на основний матеріал теми. Студенти низького рівня розробляють одне завдання репродуктивного типу. Зібрана інформація та доробки студентів упорядковуються у вигляді електронного портфоліо.

Висновки. Вважаємо, що використання індивідуальних освітніх траєкторій дає змогу значною мірою підвищити ефективність формування інформаційної культури за рахунок індивідуалізованого підходу та сприяє професійному розвиткові майбутніх спеціалістів.

ров информатики : автореф. дис на соискание уч. степени канд. пед. наук : спец. 13.00.08 «Теория и методика профессионального образования» / В. Г. Ерыкова. - Москва, 2008. - 25 с.

4. Зверева Н. Г. Проектирование индивидуальных образовательных маршрутов студентов педвуза на основе комплексной психолого-педагогической диагностики : автореф. дис на соискание уч. степени канд. пед. наук : спец. 13.00.08 «Теория и методика профессионального образования» / Н. Г. Зверева. Шуя, 2007. - 24 с. 
5. Левшин М. М. Педагогічна сутність поняття «інформаційна культура особистості» / М. М. Левшин // Вища освіта України. - 2002. - № 3. - С. 67-74.

6. Рогов Е. И. Настольная книга практического психолога: Учеб. пособие: в 2 кн. Кн. 2 : Работа психолога со взрослыми. Коррекционные приемы и уп-

\section{REFERENCES}

1. Antonchenko, M. O. (2004). Informatsiina kultura yak skladova zahalnoliudskoi kultury [Information culture as a part of human culture]. Kompiuterni tekhnolohii navchannia - Computer technologies of training, 9, 234-241 [in Ukrainian].

2. Bobrova, N. V. (2011). Proektirovanie individualnykh obrazovatelnykh traektoriy studentov uchrezhdeniy srednego professionalnogo obrazovaniya na osnove elektronnogo uchebnika [Designing of individual educational trajectories of students of secondary vocational education institutions on the basis of the electronic textbook]. Extended abstract of candidate's thesis. Kaluga [in Russian].

3. Yerykova, V. G. (2008). Formirovanie individualnoy obrazovatelnoy traektorii podgotovki bakalavrov informatiki [Formation of individual educational trajectory of bachelors of computer science]. Extended abstract of candidate's thesis. Moscow [in Russian].

4. Zvereva, N. G. (2007). Proektirovanie individualnykh obrazovatelnykh marshrutov studentov pedvuza ражнения / Е. И. Рогов. М. : Гуманит. изд. центр ВЛАДОС, 1999. - 480 с.

7. Семенюк Е. Л. Інформаційна культура суспільства і прогресс інформатики / Е. Л. Семенюк // HTI. - Cep. 1. - 1994. - № 7. - C. 3.

na osnove kompleksnoy psikhologo-pedagogicheskoy diagnostiki [Designing of individual educational routes of students of pedagogical universities on the basis of complex psychological and pedagogical diagnostics]. Extended abstract of candidate's thesis. Shuya [in Russian].

5. Levshyn, M. M. (2002). Pedahohichna sutnist poniattia "informatsiina kultura osobystosti" [Pedagogical essence of the concept of "information culture of a personality"]. Vyshcha osvita Ukrainy - Higher education of Ukraine, 3, 67-74 [in Ukrainian].

6. Rogov, Ye. I. (1999). Nastiolnaya kniga prakticheskogo psikhologa [Handbook of a practical psychologist]. (Vols. 1-2). Moscow: VLADOS [in Russian].

7. Semeniuk, E. L. (1994). Informatsiina kultura suspilstva i prohres informatyky [Information culture of society and progress of computer science]. NTI - STI, 7, 3 [in Ukrainian].

София Дмитриевна Рой, аспирант кафедры педагогики, Южноукраинский национальный педагогический университет имени К. Д. Ушинского, ул. Старопортофранковская, 26, г. Одесса, Украина

\section{ИНДИВИДУАЛЬНЫЕ ОБРАЗОВАТЕЛЬНЫЕ ТРАЕКТОРИИ КАК СРЕДСТВО ПОВЫШЕНИЯ ИНФОРМАЦИОННОЙ КУЛЬТУРЫ БУДУЩИХ УЧИТЕЛЕЙ}

Актуальность исследования обусловлена стремительным развитием информационных технологий и необходимостью подготовки будущих специалистов к их использованию, а также необходимостью обеспечения будущего специалиста необходимыми навыками и умениями для эффективного труда в информационном обществе. В связи с этим большое значение приобретает исследование информационной культуры личности. Высокий уровень культуры этого типа обеспечивает способность специалиста находить и обрабатывать необходимую информацию, осваивать новые информационные технологии и совершенствовать профессиональные навыки. Таким образом, формирование информационной культуры будущих специалистов в процессе профессиональной подготовки является важнейшей задачей современного образования. Цель исследования заключается в теоретическом обосновании методики применения индивидуальных образовательных траекторий как средства повышения информационной культуры будущих учителей. Под информационной культурой специалиста понимаем интегральное личностное образование, включающее в себя знания, умения и навыки владения современными информационными технологиями. Выделено три похода к трактовке понятия «индивидуальная образовательная траектория»: личностный, личностнопроцессуальный и программный. Также рассмотрена взаимосвязь понятий «индивидуальная образовательная траектория», «индивидуальный образовательный маршрут», «индивидуальная образовательная программа». В данном исследовании считаем понятия «индивидуальная образовательная траектория» и «индивидуальный образовательный маршрут» тождественными, выделяя, однако, понятие «индивидуальная образовательная программа». Индивидуальную образовательную траекторию (маршрут) понимаем как вид индивидуализации и дифференциации обучения, который проявляется в выборе студентом содержания, целей, методов и средств обучения в соответствии с его интересами, способностями и мотивациями, который реализуется в сотрудничестве с преподавателем. Индивидуальную образовательную программу трактуем как учебный план, разработанный с учетом индивидуальных особенностей ученика, который является основой индивидуального образовательного маршрута. В рамках исследования был определен уровень информационной культуры будущих учителей. В связи с низким уровнем информационной культуры студентов была предложена трехэтапная система его повышения на уроках иностранного языка с использовани- 
ем индивидуальных образовательных траекторий. Первый этап предполагает использование индивидуальных траекторий адаптивного типа и выполнение заданий репродуктивного типа. На втором этапе используются развивающие индивидуальные траектории и задания продуктивного типа. Третий этап строится на творческих индивидуальных траекториях и выполнении творческий заданий. Итоговым результатом считаем наличие у студентов умений и навыков обращения с информационными технологиями и способность к творческому их использованию.

Ключевые слова: информационная культура, индивидуальная образовательная траектория, индивидуальный образовательный маршрут, индивидуальная образовательная программа, будущие учителя.

Sofiia Roi,

post-graduate student, Department of Pedagogy, South Ukrainian National Pedagogical University named after K. D. Ushynsky, Staroportofrankivska Str., 26, Odesa, Ukraine

\section{INDIVIDUAL EDUCATIONAL TRAJECTORIES AS MEANS OF ENHANCEMENT OF INFORMATION CULTURE OF FUTURE TEACHERS}

Relevance of the research is caused by rampant development of information technologies and the need for training future specialists to use them, for providing future specialists with necessary skills and abilities for effective work in information society. In this regard, the great value gets the research of personal information culture. High level of the above mentioned culture provides specialists' ability to find and process necessary information, to master new information technologies and to improve their professional skills. Thus, the formation of future specialist's information culture in the course of training is the most important problem of modern education. The purpose of the research is to justify theoretically the use of individual educational trajectories as means of improving the information culture of future teachers. Information culture of a specialist is considered as an integral personal formation that includes knowledge and skills of using modern information technologies. There are three main approaches to defining the nature of the concept of an "individual educational trajectory": personal, personal and procedural, programme. The interrelation of the concepts of "individual educational trajectory", "individual educational route", and "individual educational programme" is also considered. In this research we consider the concepts of "individual educational trajectory" and "individual educational route" identical, highlighting however the concept of "individual educational programme". We consider an individual educational trajectory (route) as a type of individualization and differentiation of training which is shown in students' choice of contents, the purposes, methods and tutorials according to their interests, abilities and motivations, which is implemented in cooperation with a teacher. An individual educational program is considered as a curriculum developed with the account of personal characteristics of a student which is a basis of an individual educational route. As part of the current research, the level of information culture of future teachers has been determined. Due to its low level, a three-stage system of enhancing the above mentioned culture at the foreign language lessons with the use of individual educational trajectories has been offered. The first stage involves the use of individual trajectories of an adaptive type and reproductive tasks. At the second stage the developing of individual trajectories and tasks of productive type are used. The third stage is based on the creative individual trajectories and creative tasks. As a result, the students should have formed abilities and skills of dealing with information technologies and their creative use.

Keywords: information culture, individual educational trajectory, individual educational route, individual educational programme, future teachers.

Рецензент: д. пед. н., проф. І. В. Бужина

Подано до редакиіiі 15.04.2016 